\title{
Sobre la creación de fronteras. El caso de La Española y las guerras del reinado de Carlos II, 1673-1697\%/
}

\section{On the Creation of Borders. The Case of the Española Island and the Wars of the Reign of Charles II, 1673-1697}

\author{
Antonio Espino López \\ ORCID iD: http://orcid.org/0000-0003-2856-3035 \\ Universidad Autónoma de Barcelona
}

\begin{abstract}
El propósito central de este artículo es analizar los acontecimientos, sobre todo de tipo militar, vividos en La Española en el transcurso de los principales conflictos del reinado de Carlos II, entre 1673 y 1697. A diferencia de otras fronteras de la Monarquía Hispánica, tanto en Europa como en las Indias, donde esta mostró una clara debilidad militar, en La Española, sobre todo entre 1690 y 1695, se produjo una cierta reacción bélica positiva, aunque de reducido alcance. Tanto es así, que en la paz de Ryswick de 1697 se terminó por ceder oficialmente la soberanía a Francia de la porción occidental de la isla.
\end{abstract}

Palabras Clave: Guerra; Frontera; Carlos II; La Española; Francia; Siglo XVII.

The central purpose of this article is to analyze the military events in the Hispaniola island in the course of the main conflicts of the reign of Carlos II, between 1673 and 1697. Unlike other borders of the Spanish monarchy, both in Europe and the Indies, where the monarchy showed its military weakness, in Hispaniola, especially between 1690 and 1695, the victory over the French forces present in the island was clear, but not definitive. So much so, that in the peace of Ryswick of 1697 was finished by officially cede sovereignty to France of the western portion of the island.

KeYwords: War; Border; Spanish Monarchy; Hispaniola; France; XVIIth Century.

Copyright: (C) 2018 CSIC. Este es un artículo de acceso abierto distribuido bajo los términos de la licencia de uso y distribución Creative Commons Reconocimiento 4.0 Internacional (CC BY 4.0).

* He podido realizar el presente trabajo merced a la ayuda recibida por parte del Ministerio de Economía y Competitividad, HAR2014-57279-P: «Conflictos religiosos y conflictos político-bélicos en tierras de frontera. El caso de la nueva frontera catalana, 1635-1789». 
Así como la paz de los Pirineos de $1659^{1}$ separó de facto Cataluña, y con ella la Monarquía Hispánica, de los condados del Rosellón y la Cerdaña, ${ }^{2}$ si bien quedó del lado hispano de la frontera una parte de esta última, La Española resultó dividida definitivamente entre ambas monarquías a resultas de la paz de Ryswick de $1697 .{ }^{3}$ Son dos ejemplos muy apartados en el espacio, pero no en el tiempo, de aparición de una nueva frontera que se debió consolidar militarmente. ${ }^{4}$ Mientras la paz de Nimega de 1678 y la tregua de Aquisgrán de 1684 afianzaban la posición francesa en el Pirineo catalán (pues durante los años bélicos de 1667-1668 y 1674-1677 una parte de las conquistas pirenaicas de Luis XIV aun estuvo militarmente en entredicho), la presencia gala en las Antillas Mayores también tuvo sus luces y sus sombras aquellos años. Por ejemplo, y como veremos, en la década de 1680 ciertas autoridades francesas estuvieron muy dispuestas a definir de una manera definitiva los territorios ocupados por una y otra potencia en La Española. Y el siguiente conflicto entre ambas monarquías parecería a priori el mejor momento para permitirles establecer sus intereses a nivel territorial. Como es obvio, la guerra de los Nueve Años (1689-1697), o de la Liga de Augsburgo, no solo se libró en Europa sino que también dejó su impronta en los asuntos caribeños. De manera parecida a como ocurrió en el Pirineo catalán, ${ }^{5}$ en 1680, cuando se fue a comunicar al gobernador de La Tortuga las paces firmadas en Nimega a fines de 1678, se habló de «la incompatibilidad y los daños que podrán resultar de que en esta isla habiten dos naciones tan diferentes». ${ }^{6}$ Por cierto que entre los habitantes de la Cerdaña dividida entre las monarquías hispánica y gala hubo después de 1660 esa misma «relación muy fluida y ambivalente que oscilaba entre la violencia abierta y la colaboración», que Ponce Vázquez detecta en La Española entre residentes franceses e hispanos en las últimas décadas del siglo XVII. Por lo tanto, las similitudes son más de las que hubiésemos podido imaginar. ${ }^{7}$

1 Entre la abundante producción acerca del tratado de los Pirineos y sus consecuencias, véanse en su totalidad las obras de Ayats, 2002, y Sanabre, 1956; 1985, 89-104; y 1989.

2 Sahlins, 1993.

3 McFarlane, 1992, 97-129. Lucena Salmoral, 1999, 52-55, 58-60 y 62-66. Boogaart et al., 1992, 184-187. Una visión general sobre La Española en el siglo XVII en Julián, 9-96.

4 Sobre la cuestión de las fronteras militares en el mundo hispánico, véanse los trabajos de Hess, 1978; Lázaro Ávila, 1997; Alonso Acero, 2000; Weber, 2000; Reichert, 2013. Y sobre las fronteras militares a nivel planetario en la época moderna, Black, 2011.

5 Espino, 2016.

6 Gutiérrez Escudero, 1985, 32.

7 Sahlins, 2002. Ponce Vázquez, 2015, cita en p. 258. 
El propósito de este trabajo es analizar los acontecimientos, sobre todo militares, vividos en La Española en el transcurso de los principales conflictos del reinado de Carlos II por ser uno de los pocos lugares donde se produjo una cierta reacción bélica positiva, aunque matizada, por parte de la Monarquía Hispánica. Se ha utilizado, además de la bibliografía que se ha estimado oportuna, fondos del Archivo General de Indias de Sevilla (AGI).

\section{La retirada hispana del Caribe}

A partir de la conclusión de la Tregua de los Doce Años (1621) la presión de piratas de diversas nacionalidades que se establecieron en pequeñas islas del Caribe, las denominadas «islas inútiles», fue en aumento. Es el caso de la isla San Cristóbal, que en 1625 fue ocupada, con intención de asentarse allá, por piratas ingleses y franceses. Tras ser expulsados por la armada de don Fadrique de Toledo en $1629,{ }^{8}$ acabaron por establecerse en la costa norte de La Española ${ }^{9}$ y en la isla de La Tortuga. De este último enclave fueron expulsados en 1635 por Ruy Fernández de Fuenmayor, pero al poco volvió a ser repoblado por el francés Levasseur. Por ello, desde 1636 se producirá una cierta militarización de La Española, organizando el gobernador Bitrián de Beaumonte las milicias criollas y prestando una mayor atención a las fortificaciones, si bien no pudieron acabarse por la mayor urgencia y necesidad de las de Puerto Rico y La Habana. ${ }^{10}$ Tras muchas tropelías cometidas por los franceses desde su base en La Tortuga sobre los habitantes de Santo Domingo, a inicios de 1654 el gobernador y capitán general de La Española, Juan Francisco Montemayor de Cuenca, ${ }^{11}$ que había organizado la milicia insular desde fines de 1653, contando esta

8 Los dos fuertes de San Cristóbal cayeron en manos españolas, recogiéndose un botín de 129 cañones, 42 morteros, 1.350 mosquetes y arcabuces con abundante munición y entre 2.000 y 3.000 hombres presos entre la isla de San Cristóbal y la de Nieves (Nevis). Véase Phillips, 1991, 276 y ss.

9 Sobre la evolución histórica de La Española desde 1605, véase Ponce Vázquez, 2015, 258 y ss.

10 Mijares y Sanz Tapia, 1990, II, 450-452. Bitrián atacó dos veces La Tortuga, la última en 1643. Torres, 1992, 179-180.

11 Juan Francisco de Montemayor nació en La Luenga en 1620 y murió en Huesca en 1685. Jurista, fue juez y auditor en Cataluña en los años de la revuelta de 1640, para pasar luego a América. Fue ordenado sacerdote en 1676. Véase su Discurso Político, Histórico, Jurídico del derecho y repartimiento de presas y despojos aprehendidos en justa guerra (México, 1658). Montemayor contó con la ayuda de dos naves corsarias holandesas que por entonces operaban en las Antillas y estaban en guerra contra Inglaterra, si bien este hecho no lo menciona en su libro-reclamación. Véase, Herrero Sánchez, 2000,361 y n. 863 . 
con poco más de quinientos hombres, venció a los franceses, que rindieron su plaza fuerte de La Tortuga.

En el transcurso de estos años, la gran presión la realizó la república inglesa durante los años de gobierno de Oliver Cromwell como Lord Protector. En 1654, tras preparar intelectual, religiosa, ideológica y políticamente la campaña, Cromwell desarrolló ante el Parlamento inglés su proyecto, denominado Western Design, para promover la expansión ultramarina inglesa comenzando con un asalto al Caribe hispano. ${ }^{12}$ Previamente, Cromwell, alarmado por el auge y empuje comercial y marítimo de los neerlandeses, había ofrecido a estos la mutua libertad de comercio y el reparto de los imperios ibéricos de ultramar, quedando toda Asia y Brasil para los neerlandeses. Esta opción fracasaría: tanto el Acta de Navegación de 1651 como la primera guerra anglo-holandesa (1652-1654) lo certifican.

Así pues, en 1655 Cromwell desencadenó su gran ofensiva sobre el Caribe sin declarar la guerra a Felipe IV. El plan consistía en atacar Cuba, Puerto Rico o Santo Domingo ${ }^{13}$ con una armada de ochenta y seis navíos, conquistar uno de estos enclaves y, desde allí, asaltar Cartagena de Indias. El ataque se dirigió contra Santo Domingo, que se defendió bien, en buena medida gracias a las desavenencias entre los mandos ingleses, y por ello pusieron rumbo hacia Santiago de la Vega, capital de Jamaica, que capituló en mayo de aquel año. ${ }^{14}$ La debilidad de la recién adquirida colonia obligó al gobierno inglés a permitir que se convirtiera en una base del filibusterismo, pues estos iban a cumplir una doble misión: defender la isla y, al mismo tiempo, mantener la presión sobre las colonias hispanas en toda la zona, y todo ello sin que la República hubiese de realizar un despliegue militar y naval notable en el área. Así, los filibusteros se bastaban para mantener a la Monarquía Hispánica a la defensiva, mientras que las tropas inglesas debían vérselas con neerlandeses y franceses. Desde Jamaica se organizaron expediciones de saqueo contra Santiago de Cuba (1662) y contra Yucatán, Honduras y Nicaragua en busca de palo de Campeche; entre 1664 y 1670 se evalúa que tomaron ocho millones de pesos en sus razias de las costas de Colombia y Venezuela, quemando,

12 Véase Pagden, 1997, 101. Armitage, 2000, 136-138.

13 Recientemente, sobre este ataque, Vega, 2013.

14 Jamaica fue atacada en 1600 por Christopher Newport, que asedió la capital sin éxito. En 1622 la escuadra de Boudewijn Hendrijks atracó en la isla, pero sin intenciones de conquistarla. Diferentes fueron las de William Jackson, quien tomo Santiago de la Vega en 1643, dejándola tras obtener un fuerte rescate. El asalto inglés de 1655 tuvo un coste muy grande: de las ochenta y seis unidades enviadas, se perdieron medio centenar y hubo 8.000 bajas entre los 12.000 hombres que conformaban la expedición. Véase, Herrero Sánchez, 2000, 359-360, n. 855. 
por último, la armada de Barlovento en la bahía de Maracaibo en $1670 .{ }^{15}$ Esta política culminará cuando, durante el reinado de Carlos II Estuardo, el corsario Henry Morgan fuese nombrado teniente gobernador de Jamaica y caballero (1670). Entre 1668 y 1671 se lanzó a duros ataques contra Portobelo, que saqueó, destruyendo, además, sus murallas; asaltó Maracaibo al año siguiente, venciendo a la flota hispana de socorro que se envió contra él, y en 1670 quemó Santa Marta y Riohacha y, poco después, cruzó el istmo de Panamá y saqueó la ciudad (1671), prueba evidente de la debilidad estratégica y militar hispana en toda la zona, a pesar de la existencia de fortificaciones y de que se había decretado la movilización general en el virreinato del Perú. Las incursiones de Morgan condujeron al tratado de Madrid de 1670, que puso fin a la guerra contra Inglaterra, reconociendo la Monarquía Hispánica la soberanía inglesa sobre los enclaves conquistados. No obstante, la colonia de Jamaica pagó un precio por ser el sostén principal de estas acciones: entre 1668 y 1671 perdió 2.600 hombres. ${ }^{16}$

En estos años, por un lado, surgirán algunas propuestas de colaboración ofrecidas por las Provincias Unidas desde la década de 1650 para atacar en el Caribe a los franco-ingleses, propuestas desechadas por Madrid al temer la intromisión holandesa en el comercio americano, ${ }^{17}$ y por otro lado, y hasta final de siglo, iba a terminar por producirse un cierto acuerdo por acabar con las acciones de los piratas, dañinos para todas las naciones presentes en el área y sin apenas operatividad militar (salvo su uso por Francia para asaltar Cartagena de Indias en 1697), mientras que ingleses, neerlandeses y franceses lucharán entre sí para destruirse sus respectivas producciones azucareras. Para Manuel Herrero,

lo que en verdad salvó al Imperio colonial español de un reparto y de una desintegración inminentes fue el éxito de su diplomacia y su habilidad para conseguir que los territorios de la Monarquía quedasen relativamente al margen de las incesantes luchas entre neerlandeses, ingleses y franceses que asolaron la zona a partir de la década de $1660 . .^{18}$

15 Herrero Sánchez, 2000, 359-361. Asimismo, los ingleses atacaron Cumaná en 1654, 1659 y 1669 , siendo siempre rechazados por la población local, igual que un asalto conjunto franco-inglés al fuerte de Araya en 1656. Por otro lado, en 1669 se intentó un desembarco en el norte de Jamaica por parte hispana para acabar con el corsarismo inglés promovido desde allá. Sobre la armada de Barlovento, sigue siendo indispensable Torres, 1981.

16 Lucena Salmoral, 1999, 72-73.

17 Estando inmersa la Monarquía Hispánica en una triple guerra contra Portugal, Francia e Inglaterra, se jugará también con la posibilidad de ofrecer ventajas comerciales a los ingleses en América para desbaratar su apoyo a la Francia de Mazarino. Véase, Herrero Sánchez, 2000, 363-372.

18 Herrero Sánchez, 2000, 362. 
Tras el final de la segunda guerra anglo-holandesa (1665-1667), Inglaterra devolvió Surinam, territorio que había ocupado desde hacía quince años. Y al finalizar la tercera guerra anglo-holandesa (1672-1674), Inglaterra retuvo todas sus posesiones, mientras que solo por la paz de Ryswick de 1697 la Monarquía Hispánica cedió el tercio occidental de La Española a Francia (Saint Domingue). ${ }^{19}$

\section{Las guerras de Holanda y Luxemburgo, 1673-1684}

Los primeros años del reinado de Carlos II azotaron terriblemente la isla. Hubo epidemias en 1666 y 1669 que diezmaron sobre todo, pero no solo, la población esclava de origen africano, de ahí que se fomentara la emigración de población de origen canario desde 1679, cuyos primeros pobladores arribaron en 1684. Hubo huracanes en 1666 y 1672 especialmente dañinos y un terrible terremoto en 1673 que arruinó un tercio de las casas de la ciudad de Santo Domingo y afectó las murallas, en especial un baluarte. ${ }^{20}$

En 1673 la Monarquía Hispánica comenzó su participación en la guerra de Holanda. Un año antes, para proteger mejor La Española, ya se enviaron desde Nueva España ciento treinta infantes con municiones suficientes y la paga de un año. ${ }^{21}$ Una de las primeras acciones hispanas fue atacar en diciembre de 1673 el asentamiento galo de la isla, quemando la mitad de las casas que se encontraban en el llamado por los franceses cuartel «del Cap», el más cercano al centro hispano de la isla, «y mataron a quantos hallaron en ellas, de suerte que desde aquel tiempo nuestros [h]abitantes no vuelven a dormir en ellas», se dice en una memoria francesa sobre Santo Domingo de 1676 que cayó en manos del gobernador Padilla Guardiola y se tradujo. En dicha memoria se añade que si hubiesen persistido en sus ataques, habrían logrado ocupar toda la isla debido a la dificultad para su gente de unirse para la defensa por estar diseminados en sus labranzas. Para las autoridades galas un gran problema era la falta de población, un fantasma, también, como veremos, para las hispanas, ${ }^{22}$ pues buena parte de los bucaneros de la isla se habían ido marchando al no encontrar tantas reses bravas como

19 McFarlane, 1992, 97-129. Lucena Salmoral, 1999, 52-55, 58-60 y 62-66. Boogaart et al., 1992, 184-187.

20 Gutiérrez Escudero, 1985, 16-22, 42. Ponce Vázquez, 2015, 263.

21 Hanke y Rodríguez, 1978, V, 34-40.

22 En La Tortuga habría 6.500 residentes hacia 1681, mientras que los pobladores hispanos en La Española serían 6.312, una cifra quizá demasiado reducida. Ponce Vázquez, 2015, 260-261. 
antes. Sin ellos, a los que no tratan como colonos galos exactamente, no solo se perdía fuerza de combate, sino también la mejor fuente de información sobre los movimientos de los españoles en la isla. «Teníamos también entonces corsarios, que eran nuestra gente de guerra, pero casi todos se han retirado a la Jamayca, a donde viven a menor costa que en nuestras costas». En la memoria, para proteger mejor el resto del territorio dominicano, pues se hallaban trescientos de sus habitantes presos de los españoles en Puerto Rico, ${ }^{23}$ se necesitaban como mínimo otros trescientos soldados que montasen guardia en las avenidas por donde podían llegar los ataques hispanos. Se deberían repartir armas y pólvora entre los habitantes y obligarles los días de fiesta a aprender su manejo para fomentar la aparición de una milicia competente. También sería prudente introducir doscientos esclavos negros, a buen precio, en Santo Domingo con la intención de que sus habitantes, al hacerse propietarios de unos pocos, se muestren más dispuestos a trabajar y defender sus propiedades quedándose en ellas y sin ánimo de causar problemas a las autoridades y reducir «sediciones y levantamientos a que los que respiran el ayre de la América tienen el ánimo propenso». Incluso se preveía en la memoria volver a levantar la colonia Carolina de Florida, que se instaló efímeramente en tiempos de Carlos IX y el almirante Coligny, como una posible salida para los habitantes de Santo Domingo (y La Tortuga) si eran expulsados de aquellas tierras por los españoles. Incluso se añadía un detalle, como última ventaja de una conquista gala de Florida, de etnología y climatología discutibles:

Podemos también decir que como el rey de España no tiene tierra más bien poblada ni de mejores soldados que las Canarias no puede esperar menos nuestro monarca de una conquista de La Florida, supuesto que tiene un mismo clima y que todos vivimos del ayre que respiramos. ${ }^{24}$

En 1678 el presidente-gobernador Padilla Guardiola comentó los ataques producidos en la isla en lo que sería el último año de la guerra de Holanda: sesenta de sus hombres, milicias criollas de la isla, mataron una veintena de franceses y quemaron tres mil cueros de reses; dicha circunstancia le obligó a convocar hasta quinientos cincuenta efectivos, entre

23 Se trataba de los supervivientes del naufragio de un navío francés de cuarenta cañones que se iba a unir a una flota gala dispuesta a atacar Curaçao. El gobernador Ignacio de Zayas a Mariana de Austria, Santo Domingo, 26 de mayo de 1673, AGI, Santo Domingo, 66/44.

24 Memoria concerniente a la conquista francesa de la costa de Santo Domingo, AGI, Santo Domingo, 63/32. Le acompaña el original francés, de 1676. 
tropas y milicias, que quemaron varias localidades de la zona bajo influencia francesa. La esperada reacción del gobernador de La Tortuga consistió en movilizar ochocientos hombres, que atacaran como represalia la villa de Guava, donde doscientos setenta españoles la defendieron con gran pericia y sin pérdidas de su lado. Pero la noticia de la llegada del conde y almirante Jean d'Estrées con una escuadra ${ }^{25}$ le había obligado a retirar su gente a proteger Santo Domingo los últimos cinco meses -Padilla escribía en junio de 1678. Según el gobernador, la táctica ideal era someter a los franceses a un hostigamiento continuo en base a partidas de treinta hombres que, de manera constante, entrasen en su zona de influencia a lanzar correrías de la mayor intensidad que se pudiera. ${ }^{26}$

En 1681 un documento anónimo llegó al conocimiento del Consulado de Sevilla donde se razonaba acerca de la necesidad imperiosa de defender lo mejor posible La Española de la voracidad francesa, tras argumentar que la población de la zona hispana alcanzaba apenas las 6.000 personas, mientras que la población bajo soberanía gala cuadriplicaba dicho número. Todo el tráfico comercial que había con España, por un lado, y con Nueva España por otro prácticamente se había perdido, mientras la zona francesa enviaba a la metrópoli no menos de veinte navíos cargados de mercancías anualmente. Si Francia ocupaba toda la isla, como parecía ser su intención, además comenzaría a construir allí mismo flotas para acabar de robar todas la Indias, además de no poder navegar por sus aguas los navíos hispanos sino con mucho peligro; y la frase clave: las Indias hispanas no podían permitirse una segunda Jamaica. El situado era de 80.000 pesos anuales ${ }^{27}$ pero no se cobraba con puntualidad, y cuando llegaba se libraban antes las pagas de los hombres de gobierno y las primeras planas de las tropas, y ese era el gran problema. Los soldados estaban terriblemente mal pagados. En 1679 recibieron 18 pesos de paga, cuando a la mayoría se les debían 36 y 37 meses de atrasos, «y a muchos soldados viejos 6 y 7 años, por cuia raçón los soldados que llevan a aquella isla de España y Nueva España se huyen luego porque andan desnudos y muertos de hambre y esto no se puede

25 La noticia que daba don Juan Padilla era que D’Estrées, con dieciocho navíos y 6.000 hombres, les había ganado a los neerlandeses la isla de Tobago en diciembre de 1677. Padilla Guardiola a Carlos II, Santo Domingo, 1 de febrero de 1678, AGI, Santo Domingo, 63/32.

26 Padilla Guardiola a Carlos II, Santo Domingo,12 de junio de 1678, AGI, Santo Domingo, 63/32.

27 Una cifra que desmiente Rafal Reichert a partir de otra documentación del AGI. Según los datos que aporta, entre 1672 y 1683 el situado era de 61.049 pesos para cubrir una dotación de 362 plazas; y entre 1684 y 1700 se fijó en 70.311 pesos para una dotación de 418 plazas. Reichert, 2012 a, 71. 
remediar», sino era enviando año tras año el situado acordado. En cuanto a la despoblación, aparece la idea de enviar a residir a La Española a los habitantes de las islas Canarias que en el presente estaban «pereçiendo y viviendo en las concavidades de las laxas de los montes por no tener tierras en qué vivir ni cultivar». Además, si aumenta la población también podrá hacerlo el número de soldados dispuestos a pelear en su nueva tierra hasta expulsar totalmente a los franceses. ${ }^{28}$

En realidad, ya en julio de 1680 había escrito a Carlos II el presidente-gobernador Francisco Segura avisando de la llegada de una escuadra de nueve navíos al mando del almirante D'Estrées con la excusa de un canje de prisioneros tras el final de la guerra de Holanda, al que Segura se negó por ser piratas, es decir, gente práctica en aquellas tierras y aguas, que podrían proporcionar valiosa información a D'Estrées, ello sin contar la sospecha del gobernador acerca de la presencia gala: solo querían comprobar la capacidad defensiva de Santo Domingo, que era muy reducida. Y Segura adelantó una idea que una década más tarde, como veremos, pondría en práctica el gobernador Pérez Caro: con dos mil hombres por tierra, pero con la ayuda de unidades de la marina se podría recuperar aquella isla de manos de Francia. ${ }^{29}$ ¿El anónimo antes analizado era obra suya, o de alguien con quien hubiera tratado aquellas cuestiones? En un impreso inspirado por Segura, quien llegó a viajar a la corte, de 1683 o 1684 — pues trata en el mismo sobre el ataque a Veracruz del pirata Lorencillo, el mulato neerlandés Laurents de Graaf, ocurrido en 1683 — , no se hablaba de 24.000 franceses en La Española, sino de 10.000, quienes habían establecido desde La Tortuga hasta diecisiete poblaciones en la isla vecina. Segura reclamaba un gasto de 300.000 pesos para enviar a la ínsula mil familias de las islas Canarias, ochocientos infantes y pagar una armada de seis u ocho bajeles para limpiar aquellas aguas de piratas; Segura creía que había setenta naves piratas en las Indias en aquellos momentos. Para facilitar la tarea, ofrecía la lista de todas las islas y factorías ocupadas por las potencias extranjeras

28 Papel anónimo, Sevilla, 1 de octubre de 1681 y carta del Consulado sevillano del 7 de octubre de 1681, AGI, Santo Domingo, 63/32. El Consejo de Indias resolvió que el situado anual llegado a La Habana se repartiese cada año tanto a Puerto Rico como a Santo Domingo utilizando alguna unidad de la armada de Barlovento. Por otro lado, la idea de enviar población canaria a repoblar Santo Domingo ya se había escuchado otras veces, pero nunca se llegó a poner en práctica. Incluso, en 1693, se habló del envío de mallorquines y napolitanos que, a modo de corsarios, defendiesen aquellas costas. Al respecto, véase, Julián, 2014, 87-89. go, 63/32.

29 Francisco Segura a Carlos II, Santo Domingo, 22 de julio de 1680, AGI, Santo Domin- 
en las Indias, la prueba más evidente de la derrota hispana: los neerlandeses ocupaban las islas de Tobago, Granada, Bonaire, Curaçao, Aruba, Mari Galante, la Deseada, Guadalupe, Antigua, Nieves, San Bartolomé y Santa Cruz. Inglaterra poseía Jamaica, Barbados, San Cristóbal, Anguila, cuatro islas de las Bahamas y las Bermudas. Francia se asentaba en San Vicente, Santa Lucía, Matalino o Martinica, La Tortuga, Caimán y en la zona occidental de La Española. Y los daneses la Virgen Gorda. Todo ello sin contar sus factorías en tierra continental. ${ }^{30}$

En 1684, ante la ruptura de la guerra en Europa (guerra de Luxemburgo), el presidente-gobernador de Santo Domingo, el maestre de campo Andrés de Robles, informaba de que los franceses ya tenían noticia de la ruptura de la paz y se habían apartado de la «frontera» establecida, no sin antes haber robado todos los ganados que habían podido. Siguiendo las órdenes recibidas, pues se daba por hecho que había diez mil bucaneros poblando la parte francesa de la isla, Robles envió centinelas lo más cerca posible de sus localidades para ser informado con tiempo de cualquier novedad. ${ }^{31}$ Pero en noviembre, cuando la tregua de Ratisbona ya se había firmado en Europa, Robles escribía explicando cómo el gobernador francés del Guarico, la zona ocupada por los galos, le había escrito para preguntarle sobre cómo pensaba plantear la guerra, pues le aseguraba, y es lo más significativo, que tenía «poder de Francia para demarcar la tierra desta ysla, porque de aquí le avían propuesto que si yo le tenía estava llano a hacerlo». Lógicamente, Robles contestó con una rotunda negativa. ${ }^{32}$ Añadía las noticias de haber visitado la isla dos oficiales de Luis XIV, el comendador de San Lorenzo, general del Rey Sol en las islas, y el intendente general Veguen, quienes eran de la opinión de despoblar todas las islas restantes y enviar todos los efectivos a La Española para acabar de conquistarla, dadas las ventajas que tendría para ellos contar con una posición tan fuerte en las Antillas Mayores. Asimismo, dio cuenta Robles de la capacidad naval de los dos corsarios principales al servicio de Francia aquellos días, Michel de Grammont, quien había atacado la laguna de Maracaibo en 1678, último

30 Memorial en que se representa el miserable estado en que [h]oy está la isla de Santo Domingo de La Española..., sin fecha [1684], AGI, Santo Domingo, 63/32.

31 Andrés de Robles a Carlos II, Santo Domingo, 15 de julio de 1684, AGI, Santo Domingo, $63 / 32$.

32 En unos «Puntos que contiene la carta del presidente de Santo Domingo don Andrés de Robles su fecha en 23 de noviembre de 1684» (AGI, Santo Domingo, 63/32), se escribió: «la forma de [hacer] la guerra no se participa al contrario. Y que para la demarcación de los dominios de las dos Coronas, no tenía orden para hacerla, ni por sí podía executarlo». 
año de la guerra de Holanda, y el mulato neerlandés Lorencillo. El primero disponía de siete navíos, de mayor y menor porte, y el segundo de once, y podían querer atacar tanto La Española como Caracas, según noticias recabadas en Curaçao, donde muchos piratas y corsarios se reabastecían. El problema era el estado de la muralla de Santo Domingo, que estaba

toda abierta por la parte de tierra sin defensa alguna, porque lo mas de la muralla que [h] ay no la tiene, y los parapetos a pedazos en unas partes y no en otras, sin valuartes ni medias lunas, y solo seguida alguna linea con algunos recodos que encubren la bista unas partes a otras, y fuera mejor no la [h]ubiera. Y estaba de monte tan zerrada y cubierta que aun estando en ella no se beia. Y lo mismo estava la parte que mira al río. $\mathrm{Y}$ con árvoles en las mismas murallas del grueso de un hombre.

Una dejadez de mucho tiempo que Robles intentó paliar ordenando que la infantería de la plaza dedicase dos horas diarias a la limpieza de las murallas. ${ }^{33}$

En 1685, Robles se quejó amargamente de la llegada de apenas 10.000 pesos como situado después de dos años sin recibir nada desde La Habana, donde arribaba el grueso del dinero destinado a defensa proveniente de Nueva España, cuando su gobernador sin duda conocía cómo «estava esta plaça tan acavada». Tampoco podía obviarse el papel que jugaba el situado en una economía como la de Santo Domingo: «porque los naturales de ella están con suma pobreza y con el situado se socorrían todos con los gastos de los soldados». Como solía suceder, la desesperación aumentaba al ver llegar una cantidad tan reducida, cuando llegaba, y por ello aumentaban las deserciones: «Y lo peor es que los soldados se van huiendo desta miseria desde que vino el patache con los diez mil pessos de quatro en quatro y de seis en seis, que faltan ya dieziocho o veinte soldados», y le constaba que al menos dos huyeron a la zona francesa de la isla, «que les dirán todo lo que queda referido». ${ }^{34}$ Dos años más tarde, en agosto de 1687, Robles pudo escribir con satisfacción haber recibido 122.000 pesos del situado y una recluta de 246 soldados para poner aquella guarnición en una mejor situación defensiva. ${ }^{35}$

33 Andrés de Robles a Carlos II, Santo Domingo, 23 de noviembre de 1684, AGI, Santo Domingo, 63/32.

34 Andrés de Robles a Carlos II, Santo Domingo, 18 de agosto de 1685 y al virrey de Nueva España otra del mismo día, AGI, Santo Domingo, 65/24.

35 Andrés de Robles al secretario don Antonio Ortiz, Santo Domingo, 18 de agosto de 1687, AGI, Santo Domingo, 65/81. 
De todas formas, cabe decir que se lucharía duramente en La Española durante el transcurso de la guerra de los Nueve Años, 1689-1697. Uno de los pocos lugares donde se produjo una cierta reacción militar hispana exitosa en la década de 1690.

\section{El almirante Ignacio Pérez Caro ${ }^{36}$}

El almirante Ignacio Pérez Caro, presidente-gobernador de la Audiencia de Santo Domingo y capitán general de la ínsula, encontró en su llegada al cargo en 1690 una dotación de 450 infantes útiles para el servicio, pero sin contar los oficiales, así como 45 artilleros ${ }^{37}$ un número demasiado reducido pues en las defensas de aquella plaza había en aquel momento 130 piezas de artillería. ${ }^{38} \mathrm{El}$ informe obedecía a la orden de Carlos II del 17 de septiembre de 1688 por la cual todos los gobernadores debían dar cuenta lo antes posible del número exacto de tropas con las que se contaba en las diversas guarniciones de las Indias. Y si bien el número de infantes parecía suficiente a primera vista si lo comparamos con otras guarniciones, lo cierto es que se trata de un número engañoso si atendemos al hecho de que la porción hispana de la ínsula ocupaba una extensión cercana a los 70.000 $\mathrm{km}^{2}$. Por otro lado, Pérez Caro tampoco era muy optimista con respecto a la calidad de las murallas de Santo Domingo, a las que calificaba de «flacas» y los baluartes «incapaces para la defensa», y achacaba aquellos males a la falta de profesionalidad de los maestros albañiles que habían dirigido las obras, al trabajo de los soldados en las mismas y a la falta de idoneidad de la mezcla o argamasa utilizada para unir los materiales de construcción (cuatro partes de barro por solo una de cal). El gobernador solicitó 4.000 pesos

36 Pérez Caro viajó a las Indias acompañado de su mujer y sus dos hijos, de once y nueve años de edad, así como de seis criados y dos criadas de entre diecisiete y veinte años. Certificado para poder emprender el viaje con su familia, Santo Domingo, 4 de febrero de 1690, AGI, Contratación, 5452/98.

37 Un problema grave era la impericia de aquellos hombres en su oficio, por ello el presidente-gobernador ordenó que realizasen ejercicios todos los días de fiesta para aprenderlo de forma efectiva y se ganasen el sueldo que cobraban, que parecía ser su único objetivo. Pero cinco años más tarde, un desesperado Pérez Caro escribía que la situación no había mejorado y por ello «no [h]e asentado algunas [plazas] de los que [h]an muerto», y por ello solicitaba dieciséis artilleros bien formados, pues en caso de apuro siempre se podrían utilizar los vecinos de la ciudad y los artilleros de los navíos que hubiese en el puerto. Pérez Caro a Carlos II, Santo Domingo, 12 de diciembre de 1695, AGI, Santo Domingo, $66 / 82$.

38 Pérez Caro a Carlos II, Santo Domingo, 2 de julio de 1690, AGI, Santo Domingo, 65/209. Ciento veinticinco piezas dijo haber el gobernador Padilla Guardiola en febrero de 1678. Padilla Guardiola a Carlos II, Santo Domingo, 1 de febrero de 1678, AGI, Santo Domingo, 63/32. 
extra en el situado de Nueva España hasta acabar aquellas obras. ${ }^{39}$ Tampoco dejó de señalar Pérez Caro la existencia de apenas 2.400 hombres en su jurisdicción con capacidad para portar armas, cuando el enemigo francés se sabía que había aumentado su número notoriamente en los últimos tiempos, y se debía enviar ayuda militar a localidades situadas a cuarenta y sesenta leguas de la capital, y por caminos fragosos. Santiago de los Caballeros, por ejemplo, solo tenía como guarnición un cabo y dieciséis soldados, cuando necesitaba como mínimo, al igual que Guaba, por su cercanía al territorio galo, medio centenar de mosqueteros. En definitiva se precisaba un situado acorde a la cantidad de gente que en aquel momento servía en la isla, pues el actual, 20.000 pesos, apenas si cubría las necesidades de la pagas de trescientos efectivos, cuando había que abonar, además, otras muchas cosas, como el arreglo de las cureñas de las artillerías. ${ }^{40} \mathrm{El}$ caso es que el gobernador francés, De Cussy, pudo atacar Santiago de los Caballeros con una fuerza notable, 2.600 infantes y un escuadrón de medio millar de caballos, destruyendo la localidad mediante el fuego en apenas doce horas que duró su ocupación, salvándose tan solo setenta y dos hogares, de un total de doscientos bohíos y treinta casas de piedra. ${ }^{41}$

\section{Anatomía de una victoria, enero de 1691}

A diferencia de otras oportunidades, Pérez Caro supo organizar una respuesta a la altura de lo acontecido. De entrada, reclamó la presencia o bien de la armada de Flandes, al mando del almirante Papachino, o bien de la armada de Barlovento, pues era consciente que solo una respuesta terrestre iba a ser insuficiente a la larga frente a tamaño enemigo. El caso es que el 21 de enero de 1691 se produjo un choque en la zona occidental de la isla (el Guarico), en esa nueva frontera militar establecida, pero aun no fijada por un tratado internacional. La acción de represalia se saldó, siempre según Pérez Caro, con seiscientas bajas del lado galo — si bien en otra relación nuestro hombre refirió cuatrocientas bajas-, mil casas incendiadas y ciento cuarenta esclavos negros capturados. Es interesante la constatación,

39 Pérez Caro a Carlos II, Santo Domingo, 4 de junio de 1690, AGI, Santo Domingo, 65/210.

40 Pérez Caro a Carlos II, Santo Domingo, 12 de junio de 1690, AGI, Santo Domingo, 65/211.

41 Resumen para la Junta de Guerra de Indias del 15 de septiembre de 1691 de las cartas previas enviadas por Pérez Caro el 6 de agosto de 1690 y 12 de octubre de 1690, AGI, Santo Domingo, $65 / 215$. 
exagerada, del presidente-gobernador de que Francia desde su posición en La Española aspiraba a la monarquía absoluta en las Indias, cuando los aliados ingleses en este conflicto, pero enemigos en otros muchos, lo habían intentado a su manera también desde Jamaica. Por otro lado, era consciente de la enorme dificultad para Luis XIV de enviar ayuda a su gente en la isla a causa «de las grandes guerras que tiene en la Europa», como si Carlos II no las tuviera. Pero fue, sin duda, en el ánimo y el buen hacer de Pérez Caro donde se encontraba la base del triunfo, pues en el informe de la victoria dirigido a su monarca señaló cómo «en todas materias y en especial en las de guerra es regla prudencial no perder las ocasiones que prometen buen suceso». Movilizó 1.300 hombres al mando del maestre de campo general Francisco de Segura y contó con el apoyo de la armada de Barlovento y sus ocho embarcaciones, que en el puerto de Manzanillo, entre el 14 y el 16 de enero, embarcó trescientos lanceros, además de las tropas que ya iban a bordo, para que fueran desembarcados en la posición más favorable para impedir que el enemigo enviase ayuda a la primera línea de combate. Exagerando menos de lo que parece, el gobernador calificó el día de la victoria como «el más glorioso y plausible que de 35 años a esta parte [h]a celebrado La Española y toda la rexión austral americana». Se enfrentaron a una fuerza gala de ochocientos hombres formada en escuadrón en La Limonade, la primera población de los franceses en su zona de la isla. Pérez Caro asegura que su gente formó en una primera línea con trescientos arcabuceros, mosqueteros y escopeteros, y dos líneas en fondo con quinientos lanceros, aunque en uno y otro flanco colocó las «tropas volantes», en terminología de la época, es decir un grupo indeterminado de milicianos recogidos por el camino del norte y sur de la isla. La táctica francesa, que consistió en alargar al máximo su frente para intentar desbordar los dos flancos del contrario y rodearlo, no tuvo éxito cuando el maestre de campo general Segura ordenó mezclar lanceros con arcabuceros y mosqueteros en un solo avance. El resultado fue la victoria causando 258 bajas al enemigo en aquel encuentro, y entre ellos el gobernador De Cussy y sus principales lugartenientes, pero los trescientos lanceros desembarcados consiguieron aumentar esa terrible suma a algo más de cuatrocientas bajas. Del lado hispano se produjeron 47 bajas y 130 heridos. Según los testimonios de algunos prisioneros, el error de De Cussy fue infravalorar la capacidad militar hispana y por ello no dudó en enfrentarse a fuerzas superiores. Por su parte, la armada de Barlovento, usando banderas francesas, logró acercarse a dos fragatas galas de 28 y 24 cañones, que habían ido a corsear a La Española, y las atrapó, así como a 
una fragata más pequeña de 16 cañones. ${ }^{42}$ Fue una de las más brillantes, y escasas, victorias marítimas hispanas en las Indias en los últimos decenios.

También el cabildo de Santo Domingo se apresuró a aprovechar aquellas favorables circunstancias, en las que el gran «celo» del almirante Pérez Caro tuvo mucho que ver, para intentar expulsar a Francia de la isla o, en todo caso, prepararse para aguantar un intento de venganza o «despique». Para ello solicitaron un aumento de las tropas de guarnición, el pago regular del situado —el último había sido de 70.000 pesos - para conseguir que asentasen plaza de soldado, o en su defecto no huyeran, los mejores hombres - se quejaban de que el despojo de los franceses caídos en la batalla de enero de 1691 había sido para los hombres de la armada de Barlovento, seguramente uno de los tratos hechos por Pérez Caro con los generales y almirantes de la misma- y mejorar las posibilidades de dedicarse al corso con algunos navíos de la isla. Asimismo, habría que ganar terreno en la parte occidental de la isla mediante el envío de colonos de los Países Bajos hispanos u otros vasallos de Carlos II. ${ }^{43}$

Pero seguía habiendo cuestiones por resolver, como el fenecimiento de la muralla de Santo Domingo, cuando faltaban apenas setenta varas castellanas para acabarla, no sin protestar Pérez Caro acerca de los materiales usados por su predecesor - mucho barro en la mezcla y piedra «esponjosa»; él estaba usando otros- y el hecho de tener uno de los baluartes, el de San Francisco, con una enorme brecha en su estructura que habría de subsanar cuanto antes. Y todo aquel trajín sin la presencia de un ingeniero militar, como se había solicitado. ${ }^{44}$ Solo tras una tercera carta, del 10 de noviembre, donde se abordaba este tema, la Junta de Guerra de Indias señaló que se pediría al virrey de Nueva España la remisión del ingeniero. En realidad, en los años del presidente-gobernador Andrés de Robles y en los de gobierno del propio Pérez Caro se habían gastado apenas 16.993 pesos,

42 Relación de lo sucedido, de Ignacio Pérez Caro, Santo Domingo, 14 de febrero de 1691, y Pérez Caro a Carlos II, 22 de febrero de1691, AGI, Santo Domingo, 65/223.

43 Cabildo de Santo Domingo a Carlos II, Santo Domingo, 26 de mayo de 1691 AGI, Santo Domingo, 65/223. Pérez Caro a Carlos II, Santo Domingo, 28 de mayo de 1691, AGI, Santo Domingo, $65 / 233$.

44 De hecho, en 1677 se había ahogado en su tránsito de La Guaira a La Habana el ingeniero militar Juan B. Rugero, destinado a Santo Domingo, y su ayudante se quedó en Caracas. Gobernador Juan de Padilla a Carlos II, Santo Domingo, 23 de agosto de 1677, AGI, Santo Domingo, 63/32. Rugero había sido llamado por el gobernador Zayas en 1674 cuando los vecinos de Santiago de los Caballeros le solicitaron levantar una fortaleza con su trabajo, pero siempre que alguien les diseñase la fortificación. Zayas aprovechó la coyuntura para solicitar permiso para colocar allá una guarnición de cien hombres para frenar los avances del enemigo desde el lado occidental de la isla. Ignacio de Zayas a Mariana de Austria, Santo Domingo, 13 de mayo de 1674, AGI, Santo Domingo, 65/57. 
cantidad fácilmente contrastable con los centenares de miles de pesos de coste de murallas como las de Lima o Trujillo, contemporáneas de las de La Española. ${ }^{45}$

En 1692 intentó Pérez Caro una nueva entrada en territorio francés. Para ello, contando con el apoyo de la armada de Barlovento, que desembarcó cuatrocientos mosqueteros enviados por el virrey de Nueva España, más doscientos efectivos de la Real Fuerza de Santo Domingo, pudo conseguir unirlos a poco más de novecientos hombres de las milicias criollas de la isla, alcanzando los mil quinientos efectivos, pero muchos de estos se retiraron molestos por la falta de recompensas habidas el año anterior, una frustración latente que se hizo explícita al comprobar cómo volverían a combatir con tropas de la armada. Así, el número de milites se redujo a mil cien hombres que debían atacar el Guarico, pero descubiertos por centinelas del enemigo, y ante la fama de buen soldado del sustituto de De Cussy, se ordenó frenar la ofensiva, partiendo la armada de aquellas aguas a fines de abril. Toda la movilización costó 7.000 pesos, pero al menos se tuvo sobre aviso a los franceses. Un resultado pobre, no obstante, habida cuenta de lo gastado en la operación, y sobre todo si recordamos la cifra antes proporcionada acerca del coste de lo empleado en la mejora de las murallas de Santo Domingo. ${ }^{46}$

Cuando la coyuntura le pareció oportuna, en mayo de 1693, Pérez Caro solicitó a la Corona el envío al completo de los trescientos hombres demandados tiempo atrás para poder llenar la dotación del presidio bajo su mando - una demanda aceptada por Carlos II ya el 8 de marzo de 1692-, y al mismo tiempo poder enviar refuerzos a los contingentes que vigilaban tanto el norte como el sur de la isla, que pasarían de treinta a cincuenta efectivos, además de la remisión de las armas de fuego y munición tan necesarias - doscientos mosquetes, otros tantos arcabuces y la misma cantidad de escopetas de chispa, así como cien quintales de pólvora. En realidad, solo habían llegado setenta y cinco hombres en dos compañías con sus oficiales, que, por cierto, estuvieron retenidos en Puerto Rico de septiembre a diciembre de 1692, así como apenas cien mosquetes y otros tantos arcabuces. Por otro lado, también se echaban en falta 10.500 pesos en cada uno de

45 Pérez Caro a Carlos II, Santo Domingo, 28 de mayo de 1691, 29 de julio de 1691 y 10 de noviembre de 1691, AGI, Santo Domingo, 65/236. Pérez Caro a Carlos II, Santo Domingo, 27 de agosto de 1692, AGI, Santo Domingo, 66/7.

46 Resumen de una carta del presidente D. Ignacio [Pérez] Caro del 2 de septiembre de 1692, Santo Domingo, 5 de noviembre de 1692, AGI, Santo Domingo, 66/10. 
los situados que llegaban desde Nueva España para el correcto cobro de la gente de guerra de la isla. ${ }^{47}$ Pero el problema también era que los hombres remitidos desde la Península no estaban preparados para el tipo de guerra practicada en una isla tan montuosa como La Española, cuando lo más práctico era aumentar el número de soldados reclutados entre los naturales. Una medida que no siempre era bien vista, o entendida, por la Corona. ${ }^{48}$ No obstante, en junio de 1694 Pérez Caro se hizo eco de la orden de Carlos II de conceder el perdón a todos aquellos españoles que se encontrasen encuadrados entre las tropas de los enemigos de la Monarquía. ${ }^{49}$

De todas formas, la iniciativa militar estaba del lado hispano desde la victoria obtenida en 1691, y el almirante Pérez Caro no iba a dejársela perder. En junio de 1693 informaba a Carlos II sobre los ataques protagonizados por el retén de tropas del sur de la isla, quienes había atacado en dos ocasiones el valle cercano a la isla de la Vaca, donde el pirata Lorencillo, de quien ya hemos referido su asalto a Veracruz en 1685, tenía algunos esclavos propios y de franceses trabajando en algunas tierras. El resultado fue su evacuación de dicha isla, una buena noticia si se tenían en cuenta sus muchas tropelías de los últimos años. Por su parte, el retén de tropas del norte, con treinta y seis efectivos, atacó en dirección al Guarico, quemando tierras y llevándose algunos ganados y esclavos, sin contar con la muerte de varios enemigos, entre ellos el capitán Chavel. El resultado de todas estas iniciativas era un enemigo que, para satisfacción del presidente-gobernador, «se hallaba encerrado dentro de sus poblaciones del grande temor que [h]a concevido de la continuación de estas rondas». Aquel nuevo éxito sirvió de estímulo a ciento treinta hombres, quienes desearon alistarse para formar parte de las tropas que protagonizarían un nuevo asalto en dirección a Guaba. ${ }^{50}$ Pero lo que interesaba sobre todo a Pérez Caro, un hombre de gran

47 Por ejemplo, en 1693 Pérez Caro empleó los 2.929 pesos remitidos por el virrey de Nueva España para la mejora de las murallas en dotar de cureñas a los cañones que las necesitaban; un elemento tan importante como las murallas en sí mismas. La justificación fue que no había comparecido el ingeniero militar solicitado a Nueva España para reconocer las defensas. La Junta de Guerra de Indias recordó que el virrey había recibido la orden ya en 1692, pero alegó no poder desprenderse de su único ingeniero militar. Por ello, en noviembre de 1693 la Junta designó a Gil Correoso como teniente de maestre de campo general a que pasase a la isla a cumplir con dicha tarea. $\mathrm{Al}$ final, por distintos problemas, la orden definitiva no se dio hasta mayo de 1695. Pérez Caro a Carlos II, Santo Domingo, 20 de junio de 1693 y anotación de la Junta de Guerra de Indias del 11 de enero de 1696, AGI, Santo Domingo, 66/33.

48 Pérez Caro a Carlos II, Santo Domingo, 16-18 de mayo de 1693, AGI, Santo Domingo, $66 / 24$ y $66 / 26$

49 Pérez Caro a Carlos II, Santo Domingo, 16 de junio de 1694, AGI, Santo Domingo, 66/47.

50 Pérez Caro a Carlos II, Santo Domingo, 27 de junio de 1693, AGI, Santo Domingo, 66/36. 
iniciativa, fue contactar con el gobernador inglés de Jamaica para realizar operaciones conjuntas con la armada de Barlovento y la inglesa del Caribe para limpiar la zona de franceses; una iniciativa que no gustó demasiado al virrey de Nueva España, conde de Galve, que quedaba en evidencia si no partía de él mismo el negocio. Ahora bien, la cuestión hacía meses que se discutía en las cortes de Londres y Madrid, y Pérez Caro se limitó a esperar nuevas órdenes..$^{51}$

Los acontecimientos se precipitaron cuando en diciembre de 1694 el presidente-gobernador de La Española informaba a la corte sobre el ataque francés sobre Jamaica con el desembarco de tres mil hombres, aunque la mayor parte de ellos resultaron muertos o capturados. Dicha circunstancia le llevó a enviar un contingente de hasta doscientos hombres a recorrer la parte occidental de la isla para tomar prisioneros e intentar saber algo más de los designios franceses, que no parecían afectarles por el momento. Con todo, es interesante resaltar el comentario de Pérez Caro en el sentido de tener que avanzar hasta las primeras líneas de centinelas del enemigo para intentar hacerse con algún prisionero, como se ha dicho, cuando antes recorrían con libertad toda la isla «con sus monterías»..$^{2}$

\section{La gran ofensiva de 1695}

Aparte del ataque de 1691, el hecho de armas más trascendente se produjo en 1695. Tras el infructuoso intentó galo de apoderarse de Jamaica en 1694, Guillermo III de Inglaterra y las Provincias Unidas envió una escuadra al mando del almirante Robert Willnot para que unidas sus fuerzas a las terrestres de Santo Domingo se desalojase de una vez por todas a los franceses de las Antillas Mayores. Se ha conservado un diario de la operación conjunta, un documento excepcional. No obstante, desde el principio se deja traslucir las diferencias habidas con los aliados ingleses, pues Pérez Caro no duda en atribuir a la gallardía de las fuerzas hispanas no solo buena parte de la victoria, sino que, además, una acción como aquella habría servido para restablecer el crédito de las armas de Carlos II en las Indias, y de ello deberían tomar buena nota los propios ingleses:

51 Pérez Caro a Carlos II, Santo Domingo, 22 de noviembre de 1693, AGI, Santo Domingo, 66/39. Pérez Caro a Carlos II, Santo Domingo, 17 de junio de 1694, AGI, Santo Domingo, 66/50. go, $66 / 58$.

52 Pérez Caro a Carlos II, Santo Domingo, 22 de diciembre de 1694, AGI, Santo Domin- 
«por si algún día fueren los de esta nación, se rezelen de hostilizar estas fronteras». .33

Iniciaba su informe ${ }^{54}$ Pérez Caro recordando que la falta de acción - por omisión o por desprecio del enemigo - de sus antecesores había llevado a los piratas franceses a afianzarse en el extremo occidental de la isla, esparciendo voces, creídas por muchos de manera quizá interesada, de que fácilmente alcanzarían los bucaneros los veinte mil efectivos, una cifra a todas luces falsa, pero que había servido a muchos gobernadores para mantenerse en la inacción por carecer de fuerzas competentes. Por ejemplo, Pérez Caro afirmó que tras la salida de hombres como refuerzo de la escuadra francesa que atacó Jamaica en 1694, el gobernador francés de La Española, Ducasse, apenas si se quedó con trescientos efectivos capaces para la defensa. Por otro lado, desde el principio tuvo claro que no se podía hacer la guerra sin contar con fuerzas marítimas adecuadas que bloqueasen la retirada francesa, al tiempo que se encargarían de transportar refuerzos a la parte occidental de la isla con suma rapidez y, algo muy importante, podrían retirar a sus combatientes heridos, quienes se encontrarían sin «aloxamientos a donde retirarlos, carestía de botica pues aun en esta ciudad se padece». Además, las campañas debían iniciarse, con todo prevenido se entiende, hacia diciembre para tenerlas concluidas en mayo, pues a partir de aquel momento «entran también aguas y con estas cresen muchos los ríos que median los caminos, que por su naturaleza son asperos y agrios». Él mismo desistió por aquellas causas de atacar al enemigo en 1693, cuando llegaron noticias de colaboración con la armada inglesa, pero esta no se presentó en aquellas aguas ni en ese año ni al siguiente. Tampoco la armada de Barlovento, muy disminuida de fuerza, era competente para llevar adelante una acción importante en 1694.

La oportunidad se presentó, pues, en abril de 1695 cuando alcanzó La Española una escuadra inglesa que buscaba la revancha por el ataque francés a Jamaica. Estaba compuesta por siete navíos de guerra, dos de fuego y siete de transporte de pertrechos, municiones y víveres, con 3.060 hombres entre marinería y tropas. Ante la insistencia del almirante Willnot de emprender una acción rápida por miedo a perder su gente por las muchas enfermedades tropicales, sin darles opción a combatir, o sus navíos por

53 Relación/diario de las operaciones militares en La Española, 24 de noviembre de 1695; Pérez Caro a Carlos II, Santo Domingo, 24 de noviembre de 1695, AGI, Patronato, 271/8.

54 Las siguientes páginas están confeccionadas a partir de dicho informe, que consta de treinta y cuatro folios. 
cualquier temporal, Pérez Caro obtuvo un préstamo de 16.000 pesos de los habitantes de la isla para poder mover sus tropas cuanto antes. Los pactos firmados con el almirante inglés, cuyo incumplimiento por su parte indignaría a Pérez Caro (un hombre muy religioso, quien llegaría a asegurar tener testigos entre sus enemigos que habían visto a la Virgen María avanzar con las tropas hispanas), incluían el desembarco de tropas en el puerto de Manzanillo y, en su avance, se les impedía que entrasen en cualquier templo católico, que quedaría custodiado por tropas hispanas. Así, no podría haber pillaje de ornamentos sagrados. Los practicantes de ambas religiones deberían mostrarse corteses con los rituales y creencias de sus aliados, mientras se aseguraba un reparto equitativo de todos los bienes capturados al común enemigo francés. Por otro lado, los ingleses deberían entregar al gobernador español los castillos y fortalezas que se tomaren, junto con su artillería, si bien se les pagaría oportunamente el valor de los despojos de guerra obtenidos en aquella acción conjunta. Además de prestar toda la ayuda posible a los heridos de los aliados, incluyendo su transporte a la parte oriental de la isla con su armada, los ingleses deberían hacerse cargo de los prisioneros franceses que se obtuviesen y los trasladarían a Europa, una señal inequívoca del deseo y el interés hispano por reducir la presencia gala en las Antillas Mayores.

El 8 de mayo llegó la armada de Barlovento con el situado, compuesta por tres barcos y un total de ciento doce artillerías, y desembarcó doscientos mosqueteros - de un total de 276 plazas de soldados que portaban; también se embarcaban 335 marineros-, poniéndose los navíos a las órdenes del almirante inglés, quien había partido de Santo Domingo el 23 de abril. El 19 de mayo pasó muestra Pérez Caro a su ejército y estaba compuesto por 29 compañías y 1.311 efectivos, tras movilizar suficientes bastimentos — sin necesidad, pues, de molestar a los labradores del territorio- y poder moverse todos ellos de manera competente al movilizar hasta cuatro mil animales de tiro como carruaje. El día 24, en la bahía de Manzanillo, se unieron a estas fuerzas cien mosqueteros de la armada de Barlovento, así como cien fusileros y cincuenta granaderos ingleses al mando de un sargento mayor. El día 27 se alcanzó el lugar de la batalla habida en enero de 1691 en el Guarico, por donde se avanzó en formación de combate el día siguiente una vez superados unos obstáculos, unas trincheras compuestas por empalizadas y un terraplén, realizadas por los defensores franceses. Se habló de que el famoso pirata Lorencillo había defendido la posición con seiscientos efectivos, pero se había retirado al ver el grueso de las tropas 
anglo-hispanas, no sin haber prometido la libertad a sus esclavos africanos si tomaban las armas a favor suyo. El día 29 desembarcaron seiscientos infantes ingleses, mientras los bajeles coaligados bombardeaban el actual Cap-Haïtien. Tras superar el ejército dos nuevas trincheras desamparadas, la segunda muy fuerte con cuatro piezas de artillería de cuatro libras de bala como apoyo ofensivo, las tropas entraron en Port-de-Paix. El lugar, defendido por Lorencillo con mil efectivos, había sido desamparado por este y sus hombres, que se llevaron consigo a las montañas a sus familias y bienes. La buena disposición defensiva del lugar, con un castillo dotado de diez cañones, si bien disponía también de otras cuatro construcciones defensivas de tierra y fajina y cestones, junto con algunas trincheras con terraplenes, que contaban con no menos de veinte piezas de artillería, muchas de ellas de dieciocho libras de bala, hubiese dificultado enormemente su toma sin el gasto de mucha sangre, en expresión de Pérez Caro.

Ocupadas cinco poblaciones, a partir del día 3 de junio las tropas hispanas en número de 350 hombres comenzaron a batir los contornos por turnos, y durante tres días mataron huidos, tomaron prisioneros y quemaron todo lo que no pudieran llevarse o utilizar. El día 6 un nuevo grupo de 350 hombres emprendió idéntica acción. Dos días después, al tener noticias de que Lorencillo con doscientos hombres se encontraba emboscado en la zona, Pérez Caro ordenó al teniente general don Juan de Mieses que con 450 efectivos lo buscase. Las milicias criollas de Santo Domingo, que llevaban una rama verde en el sombrero como distintivo para distinguirse de los franceses y su gente, peleaban con lanza y machete para admiración de las tropas inglesas. Una vez enterado el gobernador Ducasse de la retirada de Lorencillo de sus posiciones defensivas, e informado de la superioridad naval y terrestre de los anglo-hispanos, no tuvo dudas de las intenciones de estos, que comenzaron a moverse hacia Port-de-Paix el 11 de junio. Una marcha lenta por la fragosidad del terreno, la falta de vituallas — si bien se hizo el aprovisionamiento que se pudo por el camino - y las enfermedades, todo lo cual maltrató «toda la más gente del exercito Británico», «[...] a cuia causa quedó sembrado el camino de cadaberes británicos», escribió con un cierto tono de regocijo Pérez Caro.

Tras el paso del río Les Trois Rivières, las tropas coaligadas atraparon a un pequeño contingente que protegía a la esposa de Lorenzillo, a quien hicieron prisionera. Hasta el 21 de junio prosiguió la marcha, pudiéndose desde aquel día abastecerse mejor las tropas en algunos lugares encontrados por el camino, hasta que el día 24 las avanzadas de los coaligados 
alcanzaron a ver Port-de-Paix, donde derrotaron a una pequeña fuerza. El día 25 se solicitó la rendición formal de la plaza, que no fue aceptada en primera instancia. Es más, en los días siguientes, desde Port-de-Paix les dispararon cuatrocientas veces con sus artillerías sin mayores consecuencias. No obstante, la enfermedad y el agotamiento se habían cobrado una dura factura entre las tropas inglesas: Willnot «tuvo el quebranto de la pérdida de más de 200 hombres y el resto de los 800 de que constaba su exército asaltado de enfermedades y el mismo General gravemente enfermo». Las pérdidas hispanas hasta entonces fueron cinco infantes y los enfermos, que también los hubo, fueron oportunamente rescatados por la armada de Barlovento.

Los ataques a Port-de-Paix se organizaron a partir de la instalación de cuatro baterías, que montaban un total de dieciséis piezas, con intención de batir la plaza desde cada flanco, mientras en el centro de la posición de los coaligados se colocaban los morteros para bombardear la posición enemiga. Las tropas se alojaron en cuarteles alrededor de la misma con la intención de cerrar los accesos por todas partes. Una serie de trabajos que se prolongaron hasta el día 28 de junio para que las tropas descansaran. Los franceses solo intentaron una salida, sin éxito, antes de comenzar el bombardeo, que se prolongó hasta el día 14 de julio, disparándose tres horas por la mañana y otras tres entre la tarde y la noche para permitir el refresco de artilleros y armas. Aunque los franceses tenían municiones y víveres para resistir seis meses, la determinación de los coaligados de rendir la plaza y el fuerte bombardeo llevó a algunos de sus oficiales a desear la capitulación, si bien De la Bale, que dirigía la defensa en ausencia del gobernador Ducasse, decidió la huida de la plaza por la noche con todos aquellos que quisieran seguirle. Entonces fueron duramente atacados y derrotados. Los franceses tuvieron en aquella huida y en el bombardeo de la plaza doscientas bajas por apenas catorce del lado hispano. Según Pérez Caro, la guarnición de la plaza era de cuatrocientos hombres con ochenta piezas de todos los calibres, siendo las murallas de cal y canto, salvo un lienzo construido a la manera de una estacada.

Por suerte la rendición no se hizo esperar más, pues a las tropas inglesas apenas si les quedaban en estado operativo doscientos hombres, cuando en sus barcos yacían cuatrocientos enfermos, junto con buena parte de la oficialidad. Con todo, se desmantelaron las defensas de Port-de-Paix, así como las trincheras y empalizadas encontradas en el camino, salvo la de Limonade. Económicamente, a Francia su derrota le reportó la pérdida de tres millones de pesos, siempre en consideración de Pérez Caro; se apresaron 
mil esclavos africanos, así como setecientos prisioneros franceses de diversas edades y sexos. El despojo también consistió, entre otros pertrechos de guerra, en setenta y una artillerías de la fortaleza de Port-de-Paix, de las cuales los ingleses cedieron veintisiete piezas. ${ }^{55}$

Hasta mediados y finales de agosto fueron retornando las tropas hispanas empleadas en el ataque, que padecieron una epidemia de calenturas, causa de medio centenar de muertes, entre ellos dos capitanes. Pero las páginas finales del informe se destinaron también a explicitar Pérez Caro no solo la fidelidad de los criollos dominicanos a Carlos II, sino también la dureza de aquella guerra, derrotados los franceses a pesar de la extrema pobreza de sus enemigos hispanos. En tiempos de guerra,

son yndesibles las necesidades que [...] padesen las mugeres e hixos de estos leales vasallos, pues no solo un día sino muchos se les pasan sin provar bocado de alimentos, porque (Señor) las mugeres de los ynfantes del presidio solo tienen el alivio del socorro de treinta reales del socorro que V. Magd. les da cada un mes. ¿Con treinta reales qué podrán comer? ¿Qué podrán calsar y pagar casa? Ya se ve que [h]a de ser muy estrechamente.

Pocos testimonios hay más claros, y de una sensibilidad tan extrema, sobre la dura vida de aquellos que dependían, junto con sus familias, de la llegada de un sueldo mísero con el situado enviado por el virrey de Nueva España.

\section{Epílogo}

Y después de todo, la potencia militar francesa en Europa se impuso, al menos ante la debilidad manifiesta de la monarquía de Carlos II. Aunque Luis XIV, como es sabido, devolvió numerosos territorios ocupados después de la paz de Nimega de 1678, y eso incluyó Barcelona, conquistada en agosto de 1697, pero no Estrasburgo, lo cierto es que una de sus compensaciones territoriales en las colonias a causa de la firma del tratado de Ryswick de 1697 fue su ocupación de la zona occidental de La Española. Así, si de momento pudo Luis XIV retener Acadia, Terranova y el territorio de la bahía de Hudson, que perdería en Utrecht en 1713, lo cierto es que las tierras del Canadá estuvieron muy cerca de la ruina aquellos años. Entre

55 Según Reichert (2012b, 178): «El balance de la campaña se cerró con 600 franceses muertos, 900 prisioneros y un botín de 1.000 esclavos, 150 cañones y más de 200.000 pesos en bienes». 
1682 y 1701 la guerra permanente contra los indios iroqueses (y sus aliados ingleses entre 1689 y 1697) hizo que Francia gastase unos recursos que no pudo enviar a otros lugares, por ejemplo el Caribe. Por otro lado, la agresiva política exterior de Francia durante el largo reinado de Luis XIV en la propia Europa está, sin duda, en el origen de su falta de respuesta ante el desafío presentado por Inglaterra en aguas y tierras americanas a partir de 1678 y, mucho más definitivamente, desde 1688. La necesidad de emplear hombres y dinero en abundancia en las guerras europeas privó a Francia de una consolidación poderosa en Norteamérica - Canadá, en 1713, solo estaba habitado por 20.000 franceses,$-{ }^{56}$ aunque siempre pudo perjudicar los intereses de la débil Monarquía Hispánica, si bien en la fase final de la guerra de los Nueve Años. Es significativo que el ataque de Pointis contra Cartagena de Indias se produzca en abril de $1697,{ }^{57}$ cuando ya tanto las Provincias Unidas como Inglaterra estaban en tratos de paz con Francia, merced a la mediación sueca, desde febrero de 1697. De hecho, Francia atacó en todos los frentes ese último año: fue la compensación de dos campañas, 1695 y 1696, a la defensiva. Las tropas galas tomaron Ath en junio de 1697 y marcharon hacia Bruselas; en América el conde de Frontenac atacaba las posesiones inglesas, D'Iberbille tomó Terranova y dos expediciones se enviaron contra Nueva York y Boston y contra la bahía de Hudson también a inicios de 1697. En la India los franceses recuperaron Pondichéry, tomada por los neerlandeses. Y como se ha señalado, hasta cierto punto el coste del retorno de Cartagena de Indias fue el reconocimiento definitivo del dominio francés sobre la parte occidental de La Española. ${ }^{58}$

Pero el inicio de la guerra de Sucesión lo cambió todo. Desde Madrid se dio orden en marzo de 1701 de que cuando llegasen navíos de la armada gala a Santo Domingo, «por su dinero se les den los bastimentos necesarios y los materiales para carenar cuando sea menester y que se les resguarde, siendo necesario, de armada mayor o enemiga». Cuando se compraron ese mismo año trescientos esclavos africanos a los franceses para trabajar en las murallas de Santo Domingo, se añadió en uno de los documentos que los marineros y oficiales de la armada gala debían ser tratados «como si fuesen españoles, pues hoy en nada se deben distinguir unos de otros». Y con la misma correspondencia, se entendía que si una parte u otra de la isla era atacada por el enemigo anglo-neerlandés, la parte no atacada acudiría a la

56 Véase el sugestivo artículo de Bernardo Ares, 2015, 28-39 y 45-46.

57 Sobre Cartagena de Indias, Serrano Álvarez, 2006.

58 Bély, 1992, 370-373. Serrano de Haro, 1996, 133-138. 
defensa de la que sí lo era. Los franceses aprovecharon aquellas facilidades dadas por la guerra en Europa para intentar redondear sus posesiones en la isla, de modo que una frontera de desconfianza apareció aquellos años y no se evanesció jamás. La joven monarquía del primer Borbón tuvo que apechar con los excesos franceses en lugares como La Española, cuando en 1702 se decía al respecto: «si esta monarquía se hallase en más robusto estado, sin infringir la paz se les podría desalojar como se había hecho otras veces en diferentes parajes, pero que la variedad de los tiempos y constitución de la Europa, obligaba a disimular mucho para no aventurarlo todo». El gobernador galo, señor de Galifet, llegó a insinuar que habría una ruda defensa si se veían atacados en sus tierras de La Española por sus aliados hispanos, y lo hizo con un añadido interesante: se defenderían «más que lo han hecho en las últimas ocasiones». ${ }^{59}$

\section{Conclusiones}

Así como la frontera hispano-francesa en el Pirineo catalán tardó mucho tiempo en establecerse definitivamente a nivel político con un tratado de límites bien definidos, desde 1659 y hasta 1678 al menos se estuvo pugnando militarmente para que la parte de la comarca de la Cerdaña anexionada a Francia por el tratado de los Pirineos retornase a la Monarquía Hispánica. Por lo demás, entre 1690 y 1697, así como entre 1707 y 1714, la Cerdaña hispana estuvo bajo control político y militar francés. Esa indefinición territorial, esa pugna, de alguna forma se vivió también en La Española. Como hemos ido viendo en las páginas precedentes, entre 1673 y 1697 los sucesivos gobernadores de La Española jamás aceptaron la presencia gala en la zona occidental de la isla, y se negaron a trazar, o a aceptar, ningún límite o demarcación que quisiesen imponer los gobernadores galos de La Tortuga. Se trataba de expulsar de todas todas al invasor, ante el riesgo de que se apoderase de toda la ínsula. A las muchas dificultades arrastradas desde el inicio del reinado de Carlos II, plagas, terremotos, huracanes, etc. que diezmaron la población y afectaron los modos y medios de vida, se añadió la guerra. Pero a diferencia de otras zonas también muy castigadas por el retroceso militar hispánico de aquellos años (Buenos Aires, San Agustín, colonia de Sacramento, Campeche, Panamá, Cumaná, Cartagena de Indias),

59 Gutiérrez Escudero, 1985, 32-35. 
en La Española se produjo el milagro, metafóricamente hablando, de frenar las apetencias galas. Como hicieran los ejércitos franceses en Europa, significativamente en el frente catalán, aquellos años, el gobernador Pérez Caro supo ver en la confluencia de fuerzas de tierra y marítimas la clave para derrotar al contrario, con el añadido de la colaboración no solo con la armada de Barlovento, sino también con efectivos de la armada inglesa. Todas esas circunstancias hicieron el de La Española un caso singular, o así lo hemos entendido. Y en definitiva, se trató de establecer, cuando - a pesar de la victoria en 1695- la paz de Ryswick de 1697 trajo la partición de la isla, una frontera no solo política sino emocional, sustentada en la desconfianza hacia el vecino. Una desconfianza que ni siquiera la guerra de Sucesión, donde lucharon como aliados franceses y españoles, supo mitigar. ${ }^{60}$

Recibido el 1 de abril de 2016 Segunda versión el 24 de noviembre de 2016 Aceptado el 18 de enero de 2017

\section{Referencias bibliográficas}

Alonso Acero, Beatriz, Orán-Mazalquivir, 1589-1639: Una sociedad española en la frontera de Berbería, Madrid, CSIC, 2000.

Armitage, David, The Ideological Origins of the British Empire, Cambridge, CUP, 2000.

Ayats, Alain, Louis XIV et les Pyrénées Catalanes de 1659 à 1681. Frontière politique et frontières militaires, Canet, Trabucaire, 2002.

Bély, Lucien, Les relations internationales en Europe, XVII ${ }^{e}$-XVIII ${ }^{e}$ siècles, Paris, PUF, 1992.

Black, Jeremy, Beyond the Military Revolution. War in the Seventeenth-Century World, Houndmills/Nueva York, Palmgrave/MacMillan, 2011.

Boogaart, Ernst van den et al., La expansión holandesa en el Atlántico, 1580-1800, Madrid, Mapfre, 1992.

Bernardo Ares, José Manuel de, «Nueva Francia y Nueva Inglaterra en el contexto de los Tratados de Utrecht (1713). Lucha por el Imperio e Historia Transatlántica», Anuario de Estudios Americanos, 72-1, Sevilla, 2015, 23-56.

Espino, Antonio, «La Cerdaña: plaza de armas de la Monarquía Hispánica en el Pirineo, 1654-1673», Historia Social, 85, Alzira, Valencia, 2016, 3-19.

Gutiérrez Escudero, Antonio, Población y economía en Santo Domingo (17001746), Sevilla, Diputación Provincial, 1985.

60 Ricardo Pattee citado por Gutiérrez Escudero, 1985, 32. 
Hanke, Lewis y Rodríguez, Celso (eds.), Los virreyes españoles en América durante el gobierno de la Casa de Austria: México, BAE, Madrid, Atlas, 1978, vol. V.

Herrero Sánchez, Manuel, El acercamiento hispano-neerlandés (1648-1678), Madrid, CSIC, 2000.

Hess, Andrew C., The Forgotten Frontier. A History of the Sixteenth-Century Ibero-African Frontier, Chicago, University of Chicago Press, 1978.

Julián, Amadeo, «Situación económica, demográfica y social de Santo Domingo en el siglo XVII», Clío, 187-I, Santo Domingo, 2014, 9-96.

Lázaro Ávila, Carlos, Las fronteras de América y los «Flandes indianos», Madrid, CSIC, 1997.

Lucena Salmoral, Manuel, Rivalidad colonial y equilibrio europeo, siglos XVIIXVIII, Madrid, Síntesis, 1999.

McFarlane, Alan, El Reino Unido y América: la época colonial, Madrid, Mapfre, 1992.

Mijares, Lucio y Sanz Tapia, Ángel, «El desarrollo histórico en las regiones», en Lucena Salmoral, Manuel (coord.), Historia de Iberoamérica, Tomo II, Historia Moderna, Madrid, Cátedra, 1990, 421-521.

Pagden, Anthony, Señores de todo el mundo. Ideologías del imperio en España, Inglaterra y Francia (en los siglos XVI, XVII y XVIII), Barcelona, Planeta, 1997.

Phillips, Carla R., Seis galeones para el rey de España. La defensa imperial a principios del siglo XVII, Madrid, Alianza, 1991.

Ponce Vázquez, Juan José, «Colaboraciones fronterizas, diplomacia y guerra en La Española, 1660-1690», Boletín del Archivo General de la Nación, XL-142, Santo Domingo, 2015, 255-284.

Reichert, Rafal, «Gastos militares que sufragó Nueva España para mantener los presidios en la región Circuncaribe durante el reinado de Carlos II, 16651700», Jahrbuch für Geschichte Lateinamerikas, 49, Viena, 2012a, 59-82.

Reichert, Rafal, «La lucha por el dominio colonial en las Indias durante el siglo XVII, casos de San Martín, Jamaica y la isla Española», Historia Caribe, 20, Barranquilla, 2012b, 159-182.

Reichert, Rafal, Sobre las olas de un mar plateado. La política defensiva española y el financiamiento militar novohispano en la región del Gran Caribe, 1598-1700, Mérida, Yucatán, Centro Peninsular en Humanidades y Ciencias Sociales-UNAM, 2013.

Sanabre, Josep, La acción de Francia en Cataluña en la pugna por la hegemonía de Europa, 1640-1659, Barcelona, Real Academia de Buenas Letras, 1956.

Sanabre, Josep, Resistència del Rosselló a incorporar-se a França, Perpiñán, Trabucaire, 1985.

Sanabre, Josep, El tractat dels Pirineus i la mutilació de Catalunya, Barcelona, Premsa Catalana, 1989. 
Sahlins, Peter, Fronteres i identitats: la formació d'Espanya i França a la Cerdanya, s. XVII-XIX, Vic, Eumo Ed., 1993.

Sahlins, Peter, «Centrar la periferia: la Cerdaña entre Francia y España», en Kagan, Richard L. y Parker, Geoffrey (eds.), España, Europa y el mundo Atlántico. Homenaje a John H. Elliott, Madrid, Marcial Pons Historia/Junta de Castilla y León, 2002, 299-317.

Serrano Álvarez, José Manuel, Ejército y fiscalidad en Cartagena de Indias. Auge y declive en la segunda mitad del siglo XVII, Bogotá, Áncora editores, 2006.

Serrano de Haro, Antonio, «España y la paz de Ryswick», Diálogos hispánicos, 16, Ámsterdam, 1995, 119-138.

Torres Ramírez, Bibiano, La armada de Barlovento, Sevilla, Escuela de Estudios Hispano-Americanos, CSIC, 1981.

Torres Ramírez, Bibiano, La marina en el gobierno y administración de Indias, Madrid, Mapfre, 1992.

Vega, Bernardo, La derrota de Penn y Venables en Santo Domingo, 1655, Academia Dominicana de la Historia, vol. XC, Santo Domingo, Editora Búho, 2013.

Weber, David J., La frontera española en América del Norte, México, FCE, 2000. 